\title{
TRATAMENTO TÉRMICO DE TÊMPERA EM AÇO ABNT 8640: ANÁLISE DAS PROPRIEDADES MECÂNICAS
}

\author{
F. SILVEIRA ${ }^{{ }^{*}}$, A. ZUCHETTO ${ }^{2}$, J. E. RUPPENTHAL ${ }^{1}$ e F. M. MACHADO ${ }^{1}$ \\ Universidade Federal de Santa Maria', Universidade Regional Integrada do Alto Uruguai e das Missões² \\ franco.da.silveira@hotmail.com*
}

Submetido 02/06/2017 - Aceito 22/02/2018

DOI: $10.15628 /$ holos.2018.5614

\section{RESUMO}

Com a constante evolução tecnológica das indústrias, os materiais ferrosos, antes de sua utilização final, são submetidos a diferentes tratamentos térmicos para proporcionar melhores propriedades mecânicas e microestruturais que o material pode adquirir. Este procedimento pode ser verificado através de componentes mecânicos no qual a dureza é uma característica fundamental no projeto. Assim, para aumentar a dureza e a resistência do material, aplica-se o tratamento térmico de têmpera. Essa técnica consiste em aquecer o material acima da temperatura crítica do aço e resfriar em água ou óleo. O objetivo do presente
\end{abstract}

estudo é analisar as propriedades mecânicas resultantes da realização do tratamento térmico de têmpera em corpos de prova de aço ABNT 8640 com o modo de resfriamento em água. Foram realizados ensaios de tração e de dureza em todas as amostras, além da análise microscópica. Comprovou-se que ocorreu o aumento da dureza nos corpos de prova, bem como a mudança estrutural dos tamanhos de grãos. Além disso, verificou-se que a têmpera, a partir de $1100^{\circ} \mathrm{C}$, resulta na redução das propriedades mecânicas do aço ABNT 8640 .

PALAVRAS-CHAVE: Tratamentos Térmicos, Têmpera, Aço ABNT 8640, Propriedades Mecânicas.

\section{TEMPER OF HEAT TREATMENT IN STEEL ABNT 8640: ANALYSIS OF MECHANICAL PROPERTIES}

\begin{abstract}
With the constant technological evolution of the industries, the ferrous materials, before their final use, are submitted to different thermal treatments to provide better mechanical and microstructural properties that the material can acquire. This procedure can be verified through mechanical components in which hardness is a fundamental feature in the design. Thus, in order to increase the hardness and strength of the material, the quenching heat treatment is applied. This technique consists of heating the material above the critical temperature of the steel and cooling in water
\end{abstract}

or oil. The aim of the present study is to analyze the mechanical properties resulting from the performance of the tempering heat treatment in ABNT 8640 steel test bodies with the cooling mode in water. Traction and hardness tests were performed in all samples, besides microscopic analysis. It was verified that the hardness increased in the specimens, as well as the structural change of the grain sizes. In addition, it has been found that annealing, starting at $1100^{\circ} \mathrm{C}$, results in the reduction of the mechanical properties of ABNT 8640 steel.

KEYWORDS: Thermal Treatments, Hardening, Steel ABNT 8640, Mechanical Properties. 


\section{INTRODUÇÃO}

As necessidades de desenvolvimento de novos materiais se intensificaram em virtude do crescimento da tecnologia nas indústrias, com a finalidade de alcançar resultados propícios para o uso em diversas áreas. A evolução das propriedades mecânicas e microestruturais dos materiais proporcionaram uma significativa melhoria para determinadas aplicações industriais e contribuíram para redução de gastos no consumo de material, no custo de fabricação e em processos operacionais para as empresas. Nesse contexto, para alcançar esses fatores que muitas vezes tornam-se diferenciais competitivos em importantes setores industriais, utilizam-se os tratamentos térmicos (Anazawa et al., 2012; André et al., 2016).

Os tratamentos térmicos são descritos como métodos empregados para modificar a estrutura interna tendo em vista uma nova formação estrutural do material (Celestino et al., 2007). São utilizados um ou outro processo em função das propriedades que pretendem-se obter na superfície. Aplicam-se esses procedimentos para controlar as microestruturas dos materiais, assim como a sua morfologia e tamanho de grão (Fontes, et al., 2015; Rocha et al., 2015). São concebidos os microconstituintes conhecidos como ferrita, bainita, martensita e austenita em razão da utilização desses métodos. Esses diferentes microconstituintes possibilitam modificar as propriedades mecânicas finais dos materiais conforme as exigências do projeto (Anazawa et al., 2012; Barros, et al., 2015). Logo, o controle da temperatura do tratamento térmico aplicado no material é fundamental e determinante para alcançar as propriedades características desejadas (Abdalla et al., 2016).

Nesse viés, para avaliar as características das propriedades mecânicas do material, aplicam-se os ensaios de resistência à tração e de dureza para possibilitar a análise da influência das diferentes temperaturas no processo de tratamento térmico. Tratam-se de ensaios destrutivos que estão relacionados à integridade geométrica e dimensional do material e são indicados para uma avaliação mais precisa de suas propriedades (Garcia et al., 2012; Blanco et al., 2015).

Para o desenvolvimento da pesquisa determinou-se como material de análise o aço ABNT 8640 que caracteriza-se por ser um aço de baixa liga. Esta classe apresenta elevada resistência mecânica e ótima temperabilidade, usinabilidade e forjabilidade (Lima, 2007). Por ser de grande aplicação nas indústrias de fabricação mecânica o aço ABNT 8640 substitui o aço ABNT 1045. Particulariza propriedades como resistência à fadiga e à fratura, quando comparado com outros materiais denota um diferencial nas seções transversais. É empregado na fabricação de engrenagens, pinos, eixos, componentes de máquinas e motores como virabrequins e pistões (Carvalho, 2004; Freitas et al., 2016).

Diante do exposto, o presente artigo consiste em analisar as propriedades mecânicas do aço ABNT 8640, resultantes da realização do tratamento térmico de têmpera através do meio de resfriamento em água. $O$ estudo assume relevância em decorrência das modificações atuais utilizadas nos tratamentos térmicos, as quais destinam-se a caracterização de propriedades estruturais relacionadas ao aumento da dureza e resistência do aço e que direcionam a obtenção de materiais cada vez melhores para satisfazer os critérios impostos pelos requisitos de projetos. 


\section{MATERIAIS E MÉTODOS}

Partiu-se de uma ideia proposta, segundo a qual o corpo de prova fosse colocado ao forno com uma temperatura superior a $1000^{\circ} \mathrm{C}$, com um resfriamento rápido, com o objetivo de se obter uma estrutura reforçada, com melhores propriedades mecânicas (Lolla et al.,2011). Para realizar essa proposição, selecionou-se um corpo de prova constituído de aço ABNT 8640 de médio carbono e baixa liga que apresenta composição química conforme a Tabela 1.

Tabela 1: Composição química (\% massa) para o aço ABNT 8640.

\begin{tabular}{c|c|c|c|c|c}
\hline $\mathbf{C}$ & $\mathbf{S i}$ & $\mathbf{M n}$ & $\mathbf{C r}$ & $\mathbf{N i}$ & Mo \\
\hline 0,40 & 0,20 & 0,85 & 0,50 & 0,55 & 0,20 \\
\hline
\end{tabular}

Para verificar a obtenção da estrutura reforçada, realizou-se a fabricação de três corpos de prova conforme especifica a norma ABNT NBR ISSO 6892-2:2013. A Figura 1 demonstra o desenho esquemático dos corpos de prova confeccionados para realizar o ensaio de tração. Dois dos corpos de prova foram levados a um forno mufla convencional sendo, portanto, designados para melhor manuseio dos mesmos como o corpo de prova sem nenhum tratamento térmico de (CP1), o corpo de prova com temperatura de têmpera de $1100^{\circ} \mathrm{C}$, denominado de corpo de prova dois (CP2) e, por fim, com temperatura de $1200^{\circ} \mathrm{C}$, de corpo de prova três (CP3).

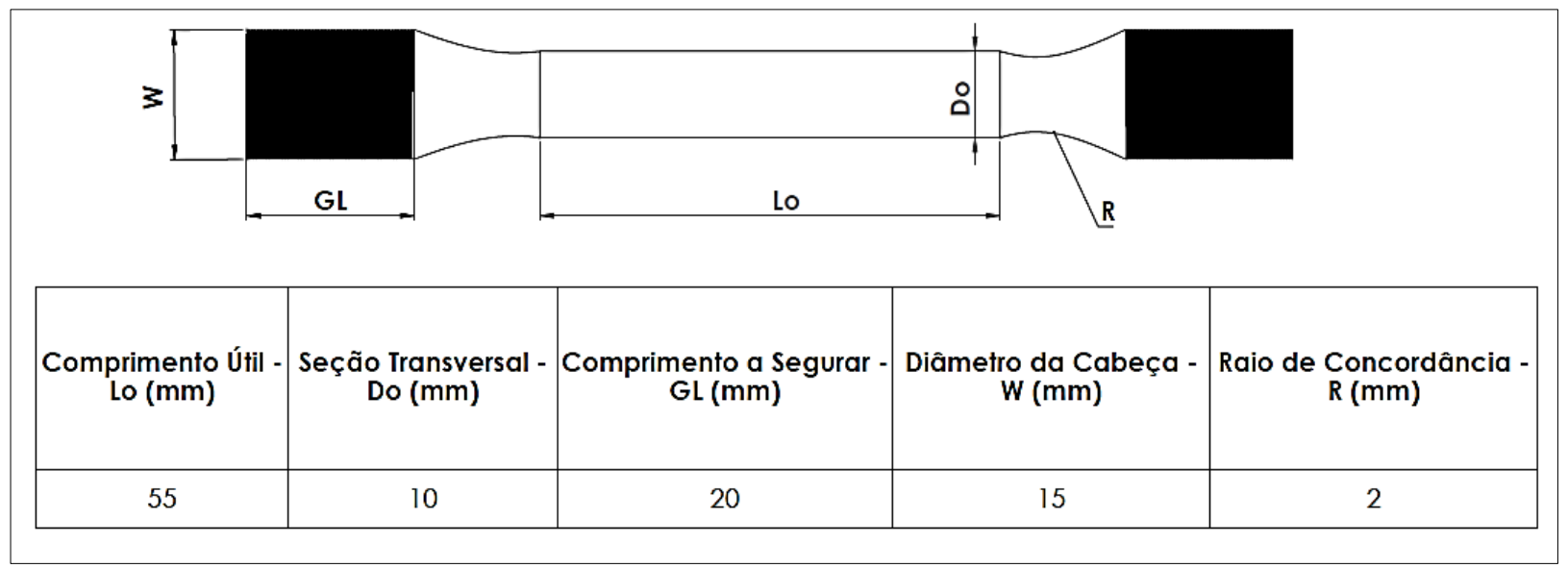

Figura 1: Representação esquemática dos corpos de prova.

Logo, para aumentar a dureza do material, utilizou-se o tratamento térmico de têmpera, que consiste em aquecer o aço em um forno com temperatura acima da zona crítica. $\mathrm{O}$ corpo de prova permanece nessa temperatura o tempo necessário para que aconteça a transformação de sua microestrutura. Após a austenitização, a peça é retirada do forno e mergulhada em água imediatamente, a fim de evitar as transformações térmicas indesejadas, tais como ferrita, cementita ou perlita, o que acarretaria em redução da dureza e ineficiência do tratamento. Durante o resfriamento do corpo de prova, os átomos de carbono ficam presos no interior da austenita, desse modo, os átomos produzem considerável deformação no reticulado cristalino da ferrita, proporcionando aumento do campo tensional do material e da dureza, obtendo-se um novo constituinte do aço, denominado martensita (Chiaverini, 2008). 
O tempo de encharque utilizado na têmpera para os três corpos de prova foi de 25 minutos, com a finalidade de que neste intervalo de tempo proceda a austenitização completa do aço. Após esse tempo, para encerrar o tratamento térmico em experimento, submeteram-nos à um resfriamento brusco em água com agitação para consolidar a mudança em suas estruturas cristalinas.

Após a realização dos procedimentos do tratamento térmico de têmpera, procedeu-se ao ensaio de tração. $O$ ensaio foi realizado em máquina universal de ensaios (série $23 \mathrm{EMIC}$ ), com célula de carga com capacidade de $300 \mathrm{KN}$. Os dados foram obtidos com o software Tesc 3.04. Esses procedimentos estão de acordo com a norma ABNT NBR ISO 6892-1:2015. O ensaio caracteriza-se como destrutivo e consiste na aplicação, em um corpo de prova padronizado, de carga uniaxial de tração com aplicação crescente de esforço até a sua completa ruptura. Os parâmetros obtidos do ensaio tratam-se do ponto de partida para a caracterização e para a especificação técnica do material (Callister, 1991). Para o presente trabalho, o ensaio ocorreu a temperatura ambiente e pode-se determinar com ele o limite de escoamento, o limite de ruptura, o alongamento e a estricção do material (Nogueira et al., 2015).

Realizadas as caracterizações do ensaio de tração, efetuaram-se os procedimentos para obtenção da microestrutura dos três corpos de prova. As amostras foram preparadas através de procedimentos metalográficos como, respectivamente: corte, embutimento, lixamento, polimento e ataque químico (Nital 3\%). Para o ataque químico, utilizou-se a técnica do microataque, a qual destaca a estrutura interior do material (Rohde, 2010). Na sequência, efetivou-se o ensaio de dureza e a medição do tamanho de grão nas amostras. Para o ensaio de dureza, utilizou-se o microdurômetro Buehler com suas respectivas amplificações.

Por se tratar de um aço duro, a escala adotada foi a de dureza Rockwell, com unidade na escala C (HRc), por ser uma escala de rápida leitura do resultado, sem a necessidade de cálculos e pela impressão que pode muitas vezes não danificar a peça ou corpo de prova que está em análise (Askeland e Phulé, 2008). O penetrador utilizado foi o cone de diamante de carga de 150 $\mathrm{Kg}$. O valor indicado na escala Rockwell trata-se do valor da dureza e refere-se à profundidade que o penetrador atingiu no material. Portanto, a profundidade decorrente da impressão resultante da carga maior é a base da medida do ensaio Rockwell (Celestino et al., 2007).

Foram assumidos dez pontos em cada um dos três corpos de prova em ensaio, com o intuito de alcançar uma maior confiabilidade na determinação dos resultados.

Desse modo, após a realização dos respectivos ensaios, através da norma ABNT NBR 11568:2016 encontrou-se o tamanho de grão das respectivas amostras referentes aos corpos de prova. Para uma análise concreta, que considera a natureza dimensional das amostras envolvidas, emprega-se o Microscópio Óptico de Reflexão (Rohde, 2010). A faixa de amplificação delimitada foi de $100 x$ para todos os casos. Com esse equipamento é possível obter imagens que permitem averiguar as propriedades microestruturais e a aparência deformada do material. Por fim, alguns resultados relevantes foram obtidos, bem como gráficos e valores de resistência à tração e de dureza, os quais são fundamentais para comprovar e validar as microestruturas de alta resistência. 


\section{RESULTADOS E DISCUSSÃO}

\subsection{Tamanho de grão}

O corpo de prova padrão (CP1) teve o menor tamanho de microgrão, pois não houve a aplicação do tratamento térmico da têmpera no mesmo. A Figura 2 representa a estrutura padrão do aço ABNT 8640 utilizado para comparar os resultados com os demais corpos de provas. Fica exposto, pela Figura 3, a diferença da variação do tamanho do grão austenítico em função da temperatura, decorrente do aquecimento dos CP2 e CP3 acima da faixa de transformação e do resfriamento rápido em água. Por ser um aço de baixa liga, sua microestrutura é formada por austenita retida e martensita que são dependentes de diversos fatores, inclusive do tamanho de grão (TG) austenítico.

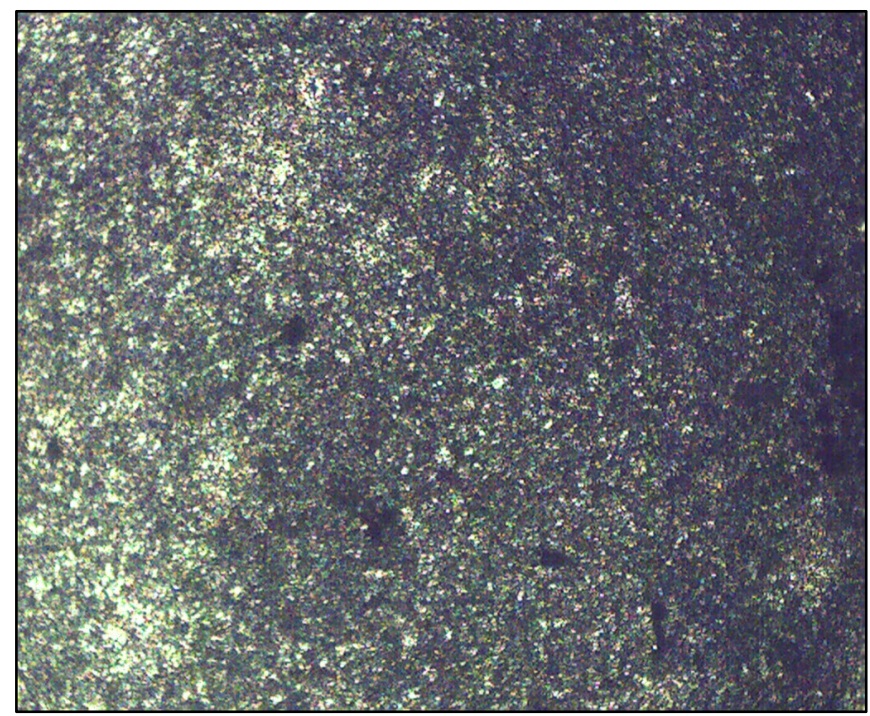

Figura 2: Aço ABNT 8640, padrão (CP1). 100X. TG 9,5.

Os corpos de prova temperados (CP2), Figura 3a, e (CP3), Figura 3b, apresentaram uma microestrutura com refino de grão maior. Caracterizam-se por proporcionar uma estrutura extremamente dura e frágil provenientes do carbono que fica retido em solução sólida. Desse modo, os átomos do carbono não conseguem migrar ou se difundir para formar a ferrita e a cementita, desenvolvendo a nova fase martensita. Deve-se ressaltar que a estrutura encontrada no CP2 diferencia-se das demais devido à temperatura a qual resultou numa distorção de átomos de carbono, provocando uma estrutura tetragonal de corpo centrado da martensita e assim, proporcionou melhores propriedades mecânicas. 


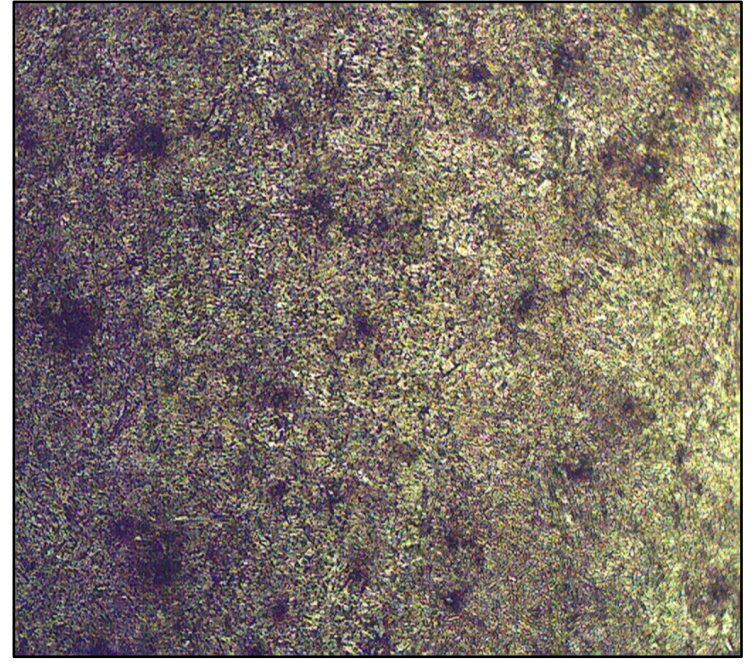

a)

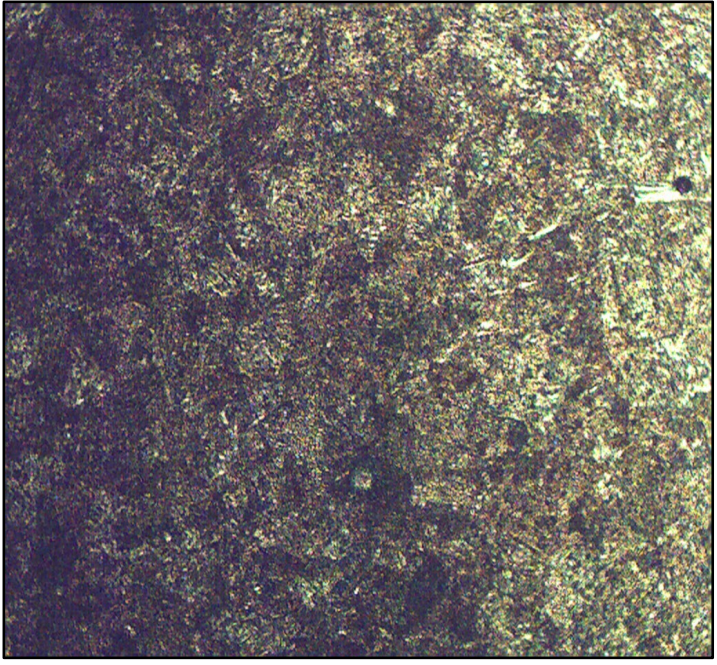

b)

Figura 3: a) Aço ABNT 8640, têmpera $\left(1100^{\circ} \mathrm{C}\right) .100 \mathrm{X}$. TG 11,5. (CP2). b) Aço ABNT 8640, têmpera (1200 $\left.\mathrm{C}\right) .100 \mathrm{X}$. TG 10,5. (CP3).

Para que a estrutura do material tenha uma uniformidade, é de extrema importância considerar no processo de têmpera a temperatura atingida em toda seção dos corpos de provas. Pois, se não ocorrer a conformidade no tratamento térmico, a têmpera pode suceder apenas na superfície do aço, influenciando os resultados das suas propriedades mecânicas.

\subsection{Dureza}

O aço ABNT 8640, por ser de médio teor de carbono, apresenta alta resistência mecânica no seu estado padrão, como exposto pelo (CP1). Quando a um ensaio de dureza na condição de têmpera esse critério proporciona um significativo aumento. Isso pode ser evidenciado na Tabela 2 , onde o (CP2) e (CP3) afirmam esse fato. Além disso, nota-se que a dureza tem boa relação com a resistência ao desgaste, embora há ensaios específicos para medir a resistência ao desgaste.

Tabela 2: Resultados referentes aos corpos de prova no ensaio de dureza.

\begin{tabular}{c|c|c}
\hline Corpo de Prova & Material & Dureza (HRc) \\
\hline $\mathrm{CP} 1$ & 8640 sem têmpera & 20,6 \\
\hline $\mathrm{CP} 2$ & 8640 com têmpera a $1100^{\circ} \mathrm{C}$ & 48,4 \\
\hline $\mathrm{CP} 3$ & 8640 com têmpera a $1200^{\circ} \mathrm{C}$ & 47,2 \\
\hline
\end{tabular}

Na Figura 4 é demonstrado de forma mais clara a variação da dureza em função das temperaturas de têmpera. Nota-se que a dureza máxima é alcançada na temperatura de $1100^{\circ} \mathrm{C}$, após isso ela apresenta uma queda significativa. Confirmando então, que esse seria o limite para alcançar uma elevada dureza. Contudo, ressalta-se que o aumento da dureza foi maior no CP2 em razão da maior decomposição da cementita na austenita, conforme ilustrado nas Figuras $1 \mathrm{e}$ 2. Com o aumento do teor de carbono a martensita resultante garante uma maior dureza. 


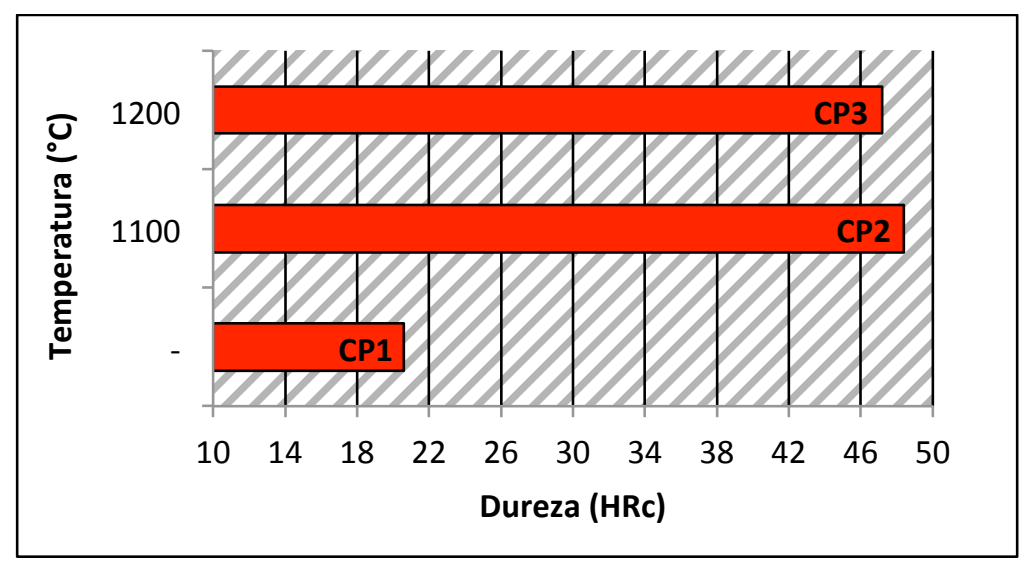

Figura 4: Gráfico da temperatura em função da dureza.

A concentração de carbono do aço ABNT 8640 limita a dureza e a sua resistência à tensão, reduzindo o seu campo de aplicação. Sua composição química constituída por manganês, silício, cromo e molibdênio contribuem para o aumento da dureza. Porém, com as altas temperaturas empregadas na têmpera o aço assumiu uma capacidade em atender as exigências mecânicas em que sua dureza elevada é fundamental.

\subsection{Propriedades mecânicas}

Inicialmente, analisou-se o ensaio de tração, concebido pelo gráfico da Figura 5, de tensão versus deformação para cada corpo de prova. Verifica-se que o CP1 apresentou comportamento dúctil, diferentemente dos CP2 e CP3 que demonstraram ser frágeis. Essa fragilidade é proporcionada pela têmpera assim como a baixa tenacidade presente em ambos. Além disso, os corpos de prova temperados não possuem limite de escoamento, o qual caracteriza-se pelo ponto onde começa a deformação plástica do aço. Nesses casos, não ocorreu a transação no regime elástico de deformação para o plástico. Por isso, a fratura ocorreu em virtude da tensão submetida aos aços ser maior que as suas resistências mecânicas.

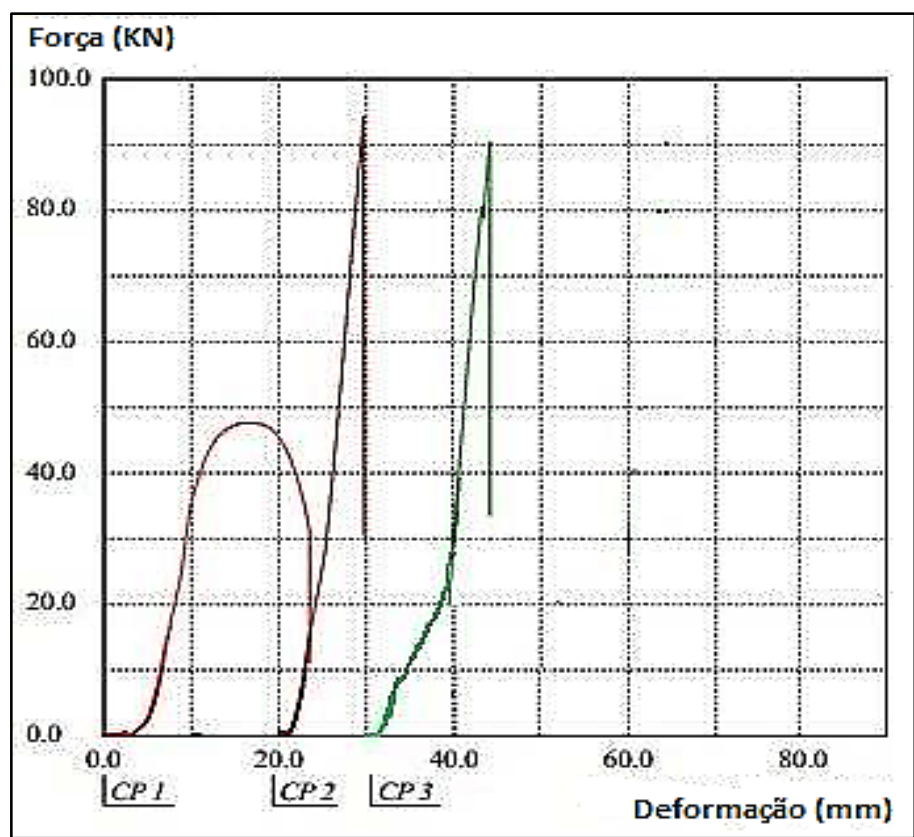

Figura 5: Gráfico da tensão em função da deformação. 
Na Tabela 3 estão expostas as propriedades mecânicas dos corpos de prova. Nota-se, que o CP2 obteve melhores qualidades se comparado ao CP3 que também foi temperado. Isso implica que, apesar de ambos não proporcionarem alongamento, a têmpera acima de $1100^{\circ} \mathrm{C}$ resultará em baixos valores pertinentes as propriedades mecânicas.

Tabela 3: Resultados atinentes às propriedades mecânicas.

\begin{tabular}{c|c|c|c}
\hline Corpo de Prova & Alongamento (\%) & Tensão de Escoamento (MPa) & Tensão Máxima (MPa) \\
\hline CP1 & 10,73 & 450,6 & 607,9 \\
\hline CP2 & 0 & 1189,6 & 1202,6 \\
\hline CP3 & 0 & 1120,8 & 1150,8 \\
\hline
\end{tabular}

A tensão máxima nos corpos de prova ocorre quando a força aplicada atua perpendicularmente à área de interesse. Como o CP1 não apresenta tratamento térmico, a tensão causa o alongamento de 10,73\% na direção da força que foi aplicada. O CP2 e CP3 não apresentam alongamento pois o objetivo é elevar a dureza e as suas tensões, com isso a força suportada foi maior e torna-se índice de medida da resistência apresentada pelo aço à deformação.

A Figura 6 demonstra as diferenças das tensões máximas e de escoamento que foram alcançadas pelos corpos de prova. As temperaturas elevadas nos corpos de prova temperados corroboram para o aumento das propriedades mecânicas. O CP2 apresentou as maiores tensões e define até que ponto o aço ABNT 8640 pode ficar sujeito à esforços mecânicos. Desse modo, fica exposto quais são as propriedades que representam a capacidade do aço de resistir à esforços aplicados sem que ocorra o seu rompimento ou a sua deformação de modo incontrolável. É importante destacar que a forma dos corpos de prova não foram alteradas para conseguir as melhorias nas qualidades do aço.

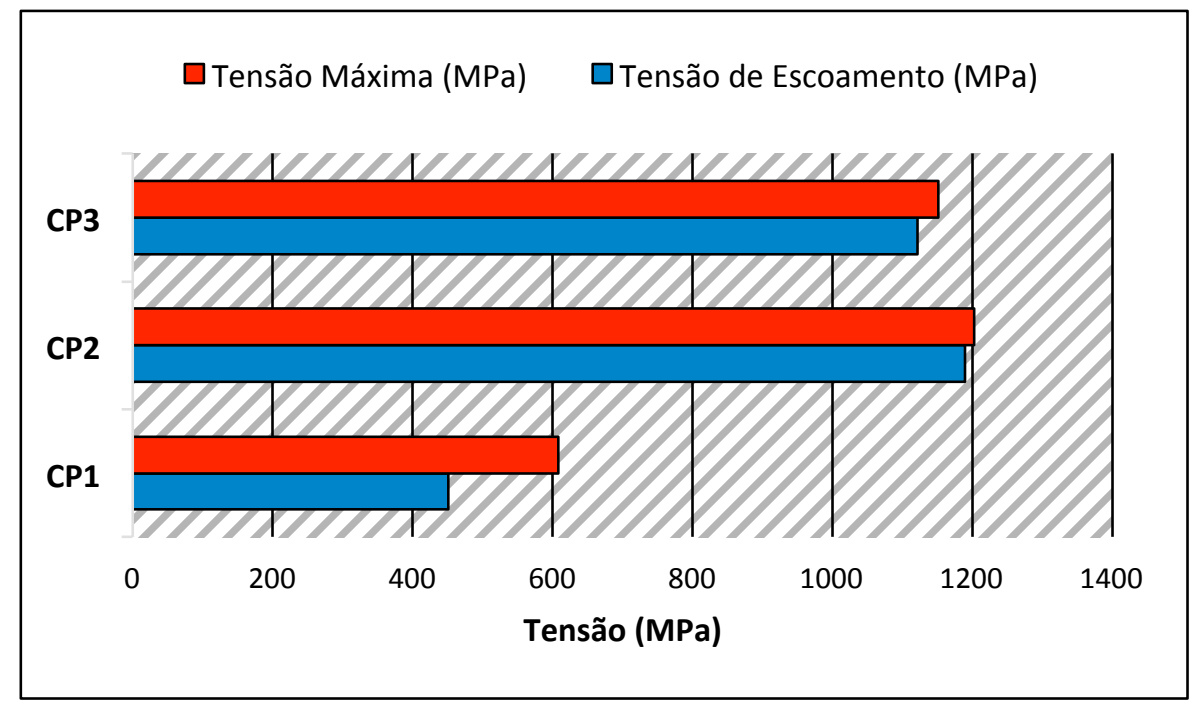

Figura 6: Tensões referentes aos corpos de prova.

Os principais resultados atingidos anteriormente são relacionados e apresentados através da Figura 7 com a intenção de possibilitar uma compreensão melhor acerca do estudo. Cada uma 
das propriedades mecânicas está associada à estrutura do material que pretende-se obter. Destaca-se o CP2 que torna-se um diferencial competitivo em projetos em que os materiais empregados precisam apresentar resistências mecânicas elevadas.

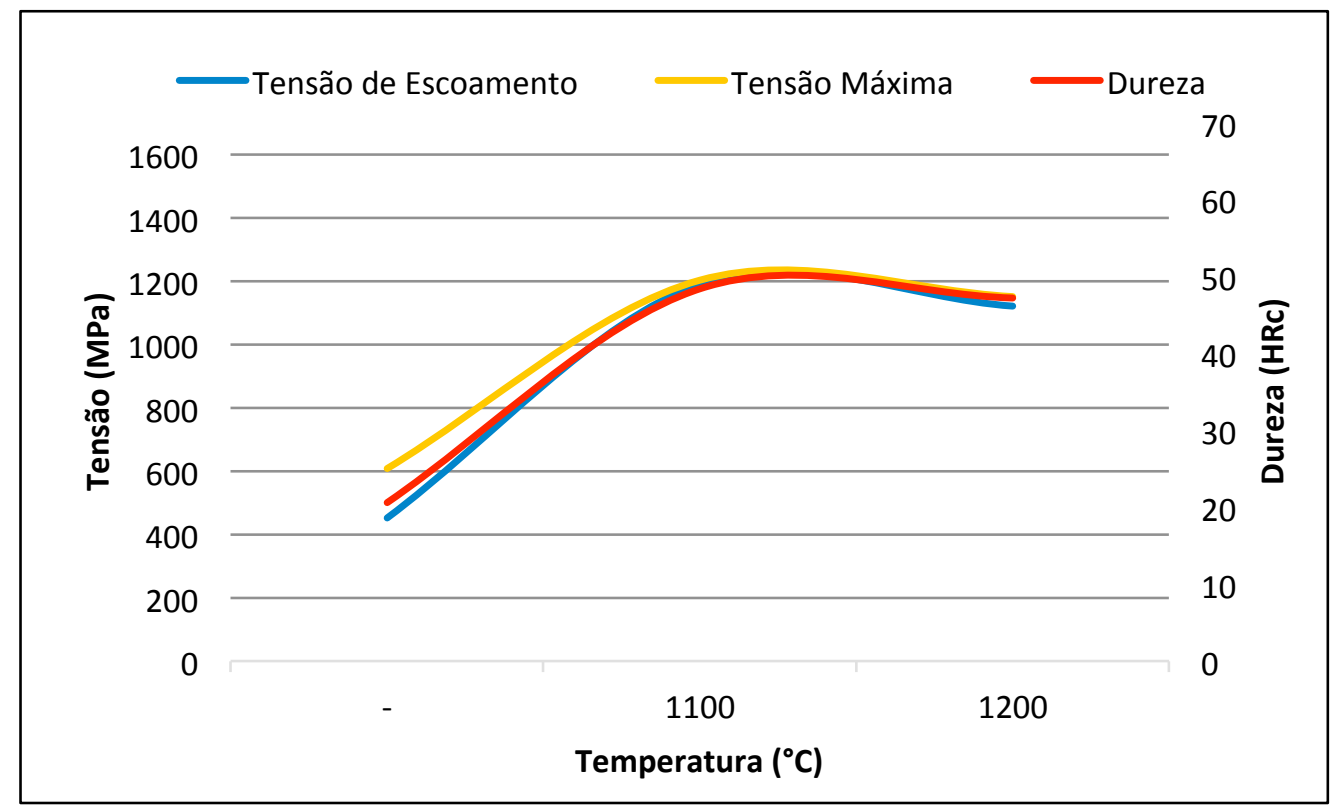

Figura 7: Comportamento do aço ABNT 8640 em diferentes temperaturas.

A partir da análise das informações é possível deduzir, para o aço estudado, que a transformação da microestrutura na temperatura de $1100^{\circ} \mathrm{C}$ foi a mais efetiva. Dessa forma, com a temperabilidade empregada no aço ABNT 8640, assim como os procedimentos experimentais, corroboram e são fundamentais para validar as microestruturas de alta resistência.

\section{CONCLUSÕES}

Com o presente estudo, nota-se que o comportamento mecânico do aço ABNT 8640 é descrito por suas propriedades mecânicas, as quais devem ser compreendidas para que seja possível desenvolver produtos cada vez melhores, possibilitando o atendimento de maneira eficaz aos requisitos impostos pelos usuários que estão cada vez mais severos. Desse modo, o ensaio de tração avaliou a resistência do aço a uma deformação aplicada lentamente, conforme representou o gráfico da força em função da deformação. As propriedades importantes neste caso são o limite de escoamento, o limite de resistência a tração (tensão máxima) e o módulo de elasticidade.

A dureza foi maior e também suas propriedades mecânicas no CP2, o qual caracterizou-se por apresentar uma fratura frágil que transcorreu em razão da propagação dos tamanhos de grãos. Com a análise micrografica fica explícita uma homogeneização da estrutura dos grãos que os outros corpos de prova não apresentaram. Desse modo, fica exposto através dos ensaios mecânicos de tração e de dureza, que até à temperatura de $1100^{\circ} \mathrm{C}$ o material irá ter boas qualidades, desprezando o alongamento, e que para diminuir tais perdas referentes à tenacidade aconselha-se fazer um revenido.

Por meio da estrutura do aço ABNT 8640 obteve-se como propósitos que a mudança de temperatura altera drasticamente as propriedades dos materiais. Neste ponto de análise, espera- 
se ter deixado claro que as propriedades do aço dependem não só de sua composição química, mas também de como são produzidos, ou seja, o que é relevante, sua estrutura interna. Nesse sentido, a pesquisa corrobora com o mundo moderno que caracteriza-se pela busca de constantes alternativas que ofereçam boas propriedades de engenharia, além dos quesitos relacionados na obtenção de materiais cada vez melhores.

\section{REFERÊNCIAS}

ABDAlLA, A. J.; GOMES, C. V.; BARBOZA, M. J. R.; SILVA, D. F.; LOMBARDO, S. (2016). Caracterização microestrutural e mecânica do aço maraging 300 soldado por processo a laser e a plasma e posteriormente envelhecido. Revista Brasileira de Aplicações de Vácuo, v.35, n. 1, p.25-30. doi: 10.17563/rbav.v35i1.1017

ABNT. Associação Brasileira de Normas Técnicas. (2015). NBR ISO 6892-1:2015. Materiais metálicos - Ensaio de tração. Parte 1: Método de ensaio à temperatura ambiente. Rio de janeiro.

. (2016). NBR 11568:2016. Determinação do tamanho de grãos em materiais metálicos - Procedimentos. Rio de janeiro, 2016.

ANAZAWA, R. M.; ABDALLA, A. J.; HASHIMOTO, T. M.; PEREIRA, M. S. (2012). Estudo comparativo das propriedades mecânicas em aços 4340 e $300 \mathrm{M}$ submetidos a tratamentos térmicos isotérmicose intercríticos. Revista Brasileira de Aplicações de Vácuo, v.31, n.1-2, p.32-37. doi: http://dx.doi.org/10.17563/rbav.v31i1-2.918

ANDRÉ, N. M.; GOUSHEGIR, S. M.; SANTOS, J. F., CANTO, L. B., AMANCIO-FILHO, S. T. (2016). Influência da Espessura do Filme Polimérico Intermediário na Resistência Mecânica de Juntas Híbridas de Alumínio 2024-T3 e CF-PPS produzidas por União Pontual por Fricção. Soldagem \& Inspeção, v.21, n.1, p.2-15. doi: 10.1590/0104-9224/SI2101.02

ASKELAND, D. R.; PHULÉ, P. P. (2008). Ciência e Engenharia dos Materiais. Editora: Cengage Learning, São Paulo.

BARROS, R. A.; ABDALLA, A. J.; RODRIGUES, H. L.; PEREIRA, M. S. (2015). Caracterização de um aço AISI/SAE 4340 com diferentes microestruturas através da técnica de tríplice ataque. Revista Brasileira de Aplicação de Vácuo, v.34, n.2, p.71-74. doi: 10.17563/rbav.v34i2.957

BLANCO, A. J.; HIGA, J. S.; NUNES, M. A.; MORAIS, W. A. (2015). Microestruturas e propriedades mecânicas de uma junta soldada obtida por processo de soldagem manual Gas Metal Arc Welding. Unisanta Science and Technology, v.4, n.2. doi: 10.1590/0104-9224/SI1903.02

CARVALHO, A. R. T. (2004). Estudo da influência da agitação e da severidade de têmpera do meio de resfriamento na determinação de velocidades críticas de têmpera. São Luís, 2004. Dissertação de Mestrado em Engenharia Mecânica, Universidade Estadual de Campinas.

CELESTINO, P. A. P.; FELIPE, R. C. T. S.; MACHADO, T. G. (2007). Análise Comparativa entre o Tratamento Térmico (Têmpera) e o Tratamento Termoquímico (Cementação) realizado em Aço 1040. HOLOS, v. 3. doi: 10.15628/holos.2007.147

CHIAVERINI, V. (2008). Aços e Ferros Fundidos: Características Gerais, Tratamentos Térmicos, Principais Tipos. Editora: ABM, São Paulo, SP, ed. 7, ampl. e rev.

FONTES, M. A.; PEREIRA, R. G.; FERNANDES, F. A. P.; CASTELETTI, L. C.; NASCENTE, P. A. P. (2015). Caracterização das camadas formadas pela nitretação a plasma em amostras de ferro 
sinterizado com e sem tratamento de ferroxidação. Revista Brasileira de Vácuo, v.34, n.2, p.54-59. doi: $10.17563 /$ rbav.v34i2.943

FREITAS, B. M.; VASCONCELOS, S. M.; MACEDO NETO, J. C. (2016). Beneficiamento do Aço SAE 8640 sob Tratamentos Térmicos. In: Anais do CONTECC - Congresso Técnico Científico da Engenharia e da Agronomia, Foz do Iguaçu.

GARCIA, A.; SPIM, J. A.; SANTOS, C. A. (2012). Ensaios dos Materiais. 2. ed. Rio de Janeiro: LTC Livros Técnicos e Científicos Editora Ltda, v. 1, 365p.

LIMA, D. R. S. (2007). Desenvolvimento de tecnologia de forjamento de aço AISI 8640 destinado à produção de brocas de perfuração. Porto Alegre, 2007. Dissertação de Mestrado em Engenharia de Minas, Metalúrgica e de Materiais, Universidade Federal do Rio Grande do Sul.

LOLLA, T.; COLA, G.; NARAYANAN, B.; ALEXANDROV, B.; BADU S. S. (2011). Development of rapid heating and cooling (flash processing) process to produce advanced high strength steel microstructures. Journal of Materials Science and Technology, v. 27, n. 5, p. 863-875. doi: $10.1179 / 174328409 \times 433813$

NOGUEIRA, R. C.; ABDALlA, A. J.; HASHIMOTO, T. M.; PEREIRA, M. S. (2015). Análise microestrutural de um aço AISI 4350 submetido a tratamentos térmicos para a formação de bainita. Revista Brasileira de Vácuo, v.34, n.1, p.44-48. doi: 10.17563/rbav.v34i1.959

ROCHA, O. F. L.; TENÓRIO, J. G.; VASCONCELOS, A. J.; MAGNO, I. B.; SOARES, E. J. (2015). Têmpera por indução eletromagnética aplicada em virabrequim de motocicleta. HOLOS, v.3. doi: 10.15628/holos.2015.2917

ROHDE, R. A. (2010). Metalografia - preparação de amostras: uma abordagem prática. Apostila didática, Universidade Regional Integrada. Disponível em: www.urisan.tche.br/ lemm/metalografia.pdf. Acesso em: 03 mar. 2016. 